2015-04

\title{
Balancing cure with comfort: palliative care in critical care.
}

\author{
Bion, J
}

http://hdl.handle.net/10026.1/13056

$10.1177 / 0269216315574648$

Palliat Med

All content in PEARL is protected by copyright law. Author manuscripts are made available in accordance with publisher policies. Please cite only the published version using the details provided on the item record or document. In the absence of an open licence (e.g. Creative Commons), permissions for further reuse of content should be sought from the publisher or author. 
Bion J \& Coombs M 2015 'Balancing cure with comfort: Palliative care in critical care' Palliative Medicine 29, (4) 288-290.

Author copy. Accepted for publication $4^{\text {th }}$ February 2015. DOI: $10.1177 / 0269216315574648$

\title{
Editorial for Special Edition: Palliative Care in Critical Illness
}

Title: Balancing Cure with Comfort: palliative care in critical care

Bion JF, Coombs M.

\author{
Dr Maureen Coombs MBE \\ Professor in Clinical Nursing (Critical Care) \\ Graduate School of Nursing Midwifery and Health \\ Victoria University \\ and \\ Capital And Coast District Health Board Wellington, New Zealand \\ Maureen.Coombs@vuw.ac.nz
}

And

Professor Julian Bion FRCP FRCA FFICM MD

Professor of Intensive Care Medicine,

University of Birmingham

j.f.bion@bham.ac.uk

Whilst critical care has historically been perceived as the antithesis of palliative care, there is growing recognition that these two clinical specialties offer important complementary skills. Both can claim that they were founded in the early 1950s, when intensive ventilator units were established to support patients suffering from respiratory failure caused by the polio epidemics sweeping Europe and North America, while at the same time Cicely Saunders was starting her training in medicine to deliver her vision of compassionate and effective palliative care for those nearing the end of their lives. Critical and palliative care have gradually converged in clinical practice, research and quality initiatives to focus on the transition from saving lives to easing the burden of terminal critical illness.

This convergence has been fostered by several factors. Critical care units have progressed from delivering single system support measures to providing complex multi-system interventions for 
patients with multiple organ failure, many of whom would not have survived forty years ago, raising expectations that death can usually be deferred. At the same time, critical care units have become a common final destination before death for the increasing proportion of the frail elderly with multimorbidity, who might, with prior knowledge, have chosen an alternative care pathway with fewer interventions and burdens. Critical care has also become more patient- and family-focused: units no longer operated severely restricted visiting hours for family members and a closed door policy for other clinical teams but now provide an intensive clinical service where collaboration within and across clinical teams is fostered and where all have a voice in a patient-centered environment. Of particular importance, patients and families have become better-empowered participants in decision-making. This is a welcome change but one which requires an informed and negotiated approach to enable patients and families to make choices about treatment options without becoming over-burdened with responsibilities. Doctors, nurses and allied health professionals in intensive care and palliative care teams bring to these difficult discussions complementary knowledge and skills which can inform and assist compassionate decision-making.

This issue of Palliative Medicine has been two years in the making and gives expression to this important collaboration. We received in excess of forty five submissions from across Asia, Australasia, North America and Europe emphasising the significant international body of work being undertaken in this area. The final selection of XX papers for publication was challenging but we have chosen high quality papers whose content can stimulate thinking and inform the practice of clinicians, researchers, educators, managers and policy makers in the field.

Several themes emerge from the papers selected for this Critical Care Special Edition. The first highlights the importance of developing a shared understanding of the goals and limits of medical interventions within healthcare professions and with the critically ill patient and their family $(1,2$, $3,4)$. This also requires a more comprehensive understanding of the role and function of contemporary palliative care services. Such 'mental models' of clinical practice must be evidencebased, culturally sensitive, and implemented in practice. Although it is possible to develop consensus on the principles of end-of-life care between professionals from widely differing backgrounds (5), the realities of practice and cultural differences may tell a different story at the bedside $(6,7)$.

The second area to emerge from this edition highlights that knowledge and developed communication skills are essential for negotiating an approach to terminal care which meets the needs of patients and families and minimizes avoidable unhappiness for them and for staff $(8,9)$. The application of knowledge in practice includes a better understanding by health care professionals and the lay public of how to translate group probabilities for survival from critical illness into individual outcomes (10) and an appreciation of factors that influence a clinician's decision making about end of life care (11). The continued importance placed on communication is well -evidenced by the many established programmes designed to maximise the effectiveness of compassionate discussions with families using structured communication tools which reduce physician variability and long-term family distress $(12,13)$. 
The third and final area reminds us that whilst excellence in care at end of life is often delivered and evaluated at the level of the individual patient, family and clinical team, organisational change is sometimes required to enable such palliative care initiatives to occur. A systems-based approach must be considered to facilitate earlier intervention to reduce undesirable outcomes $(14,15)$ and to support a more patient-focused approach at the end of life (16).

As these papers outline the developing evidence base that informs clinical practice, we can also draw some conclusions on the emerging trends and gaps in empirical work in this area. Papers published here use a range of research methods. There is representation from studies using qualitative data collection methods, survey, and cohort based non-experimental design. The research literature on palliative care in critical illness has tended to rely on these approaches with comparatively few randomized trials of interventions to improve outcomes (17). Our invited international guest who is well-placed to comment on this (18) does so in the following Editorial.

So if this Special Edition of Palliative Medicine gives insight into the developments that have occurred in the field over the past forty years, then what new challenges and opportunities do the coming decades hold? Some of these have already been highlighted here including the continued importance of communication and the need for more understanding about prognostication. Perhaps future work may include insight into complex grief patterns in the context of critical care, or greater exploration of further therapeutic interventions to support patients and families in promoting normal grieving patterns. Finally in considering the importance of bridging the scientific and clinical gap, we are reminded that end of life in critical care is an area where co-design strategies could be usefully employed to enhance the effectiveness of interventions and help develop rigorous evaluations. In using co-design strategies and processes patient, family and staff experiences can provide rich material for the development of studies and care improvement programmes and give families the opportunity to realise their potential as powerful allies in improving the quality of care at end of life. Palliative care and critical care together gives meaning to the aphorism 'cure sometimes, relieve often, comfort always'.

\section{REFERENCES}

1. Boss R et al. Novel Legislation for Pediatric Advance Directives: Surveys and Focus Groups Capture Parent and Clinician Perspectives. this issue.

2. Apostol CC et al. Association of Goals of Care Meetings for Hospitalized Cancer Patients at Risk for Critical Care with Patient Outcomes. this issue

3. Weil J et al. What's in a name? A qualitative exploration of what is understood by 'palliative care' in the emergency department. this issue

4. Heyland $D$ et al. Admission of the Very Elderly to the Intensive Care Unit: Family Members' Perspectives on Clinical Decision-Making. this issue

5. Sprung CL, Truog RD, Curtis JR, Joynt GM, Baras M, Michalsen A, Briegel J, Kesecioglu J, Efferen L, De Robertis E, Bulpa P, Metnitz P, Patil N, Hawryluck L, Manthous C, Moreno R, Leonard S, Hill NS, Wennberg E, McDermid RC, Mikstacki A, Mularski RA, Hartog CS, Avidan A. Seeking worldwide professional consensus on the principles of end-of-life care for the critically ill. The 
Consensus for Worldwide End-of-Life Practice for Patients in Intensive Care Units (WELPICUS) study. Am J Respir Crit Care Med. 2014 Oct 15;190(8):855-66. doi: 10.1164/rccm.2014030593CC.

6. Wilkinson DJ, Truog RD. The luck of the draw: physician-related variability in end-of-life decision-making in intensive care. Intensive Care Med. 2013 Jun;39(6):1128-32. doi: 10.1007/s00134-013-2871-6. Epub 2013 Feb 22.

7. Phua J, Joynt GM, Nishimura M, Deng Y, Myatra SN, Chan YH, Binh NG, Tan CC, Faruq MO, Arabi YM, Wahjuprajitno B, Liu SF, Hashemian SM, Kashif W, Staworn D, Palo JE, Koh Y; for the ACME Study Investigators and the Asian Critical Care Clinical Trials Group. Withholding and Withdrawal of Life-Sustaining Treatments in Intensive Care Units in Asia. JAMA Intern Med. 2015 Jan 12. doi: 10.1001/jamainternmed.2014.7386. [Epub ahead of print]

8. Moore NA et al . Age as a factor in do not attempt cardiopulmonary resuscitation decisions: a multicentre blinded simulation based study this issue

9. Reinhart et al. End-of-life care in the ICU: a patient-based questionnaire of ICU staff perception and relatives' psychological response this issue

10. Gigerenzer G. Risk Savvy: How to make good decisions. Allen Lane, London 2014.

11. Turnbull AE, Krall JR, Ruhl AP, Curtis JR, Halpern SD, Lau BM, Needham DM. A scenario-based, randomized trial of patient values and functional prognosis on intensivist intent to discuss withdrawing life support. Crit Care Med. 2014 Jun;42(6):1455-62. doi: 10.1097/CCM.0000000000000227.

12. Lautrette A, Darmon M, Megarbane B, Joly LM, Chevret S, Adrie C, Barnoud D, Bleichner G, Bruel C, Choukroun G, Curtis JR, Fieux F, Galliot R, Garrouste-Orgeas M, Georges H, Goldgran-Toledano D, Jourdain M, Loubert G, Reignier J, Saidi F, Souweine B, Vincent F, Barnes NK, Pochard F, Schlemmer B, Azoulay E. A communication strategy and brochure for relatives of patients dying in the ICU. N Engl J Med. 2007 Feb 1;356(5):469-78

13. Higginson IJ, Koffman J, Hopkins P, Prentice W, Burman R, Leonard S, Rumble C, Noble J, Dampier O, Bernal W, Hall S, Morgan M, Shipman C. Development and evaluation of the feasibility and effects on staff, patients, and families of a new tool, the Psychosocial Assessment and Communication Evaluation (PACE), to improve communication and palliative care in intensive care and during clinical uncertainty. BMC Med. 2013 Oct 1;11:213. doi: 10.1186/17417015-11-213.

14. Sulistio $M$ et al Hospital Rapid Response Team and Patients with Life Limiting Illness: A Multicentre Retrospective Cohort Study this issue

15. Tan A, Seah A, Chua G, Lim TK, Phua J. Impact of a palliative care initiative on end-of-life care in the general wards: a before-and-after study. Palliat Med. 2014 Jan;28(1):34-41. doi: 10.1177/0269216313484379. Epub 2013 Apr 29.

16. Coombs M; Darlington A-S; A national survey exploring views and experience of health professionals about transferring patients from critical care home to die this issue

17. Aslakson R, Cheng J, Vollenweider D, Galusca D, Smith TJ, Pronovost PJ. Evidence-based palliative care in the intensive care unit: a systematic review of interventions. Journal of Palliative Medicine 2014;17:219-35.

18. Curtis JR, Nielsen EL, Treece PD, et al. Effect of a quality-improvement intervention on end-of-life care in the intensive care unit: a randomized trial. Am J Respir Crit Care Med 2011;183:348-55. 